\title{
Fuzzy model for support investment decisions under risk
}

\author{
E V Orlova ${ }^{1}$ \\ ${ }^{1}$ Ufa State Aviation Technical University, K. Marks st. 12, Ufa, Russia, 450000
}

\begin{abstract}
One of the most important problem related to understanding the investor's behavior is to study the ways he selects, analyzes and interprets the available information and then uses it to make investment decisions. It is necessary to find out how an investor forms a certain opinion and comes to his own behavior strategy. The investor's behavioral model is variable since the financial market is volatile. The behavior of the investor is determined by a combination of rational (objective) and irrational (subjective) factors. To describe the influence of a combination of factors on the investor's behavior, a model describing this influence is needed. A formal description of interaction is complicated since a number of factors are of a qualitative nature, and the factors are also interrelated. The paper identifies the main causes and factors of irrationality in investor behavior which is the basis for its analyze and control. The fuzzy model, which allows to link a lot of behavioral factors with the utility (efficiency) of the solution is developed. Simulation results can be used for the investor's utility functions designing that is required to decisions making justification.
\end{abstract}

\section{Introduction}

It was shown [1-7] that under conditions of uncertainty and risk investors are being influenced a lot of irrational factors. The majority of financial theories [8-10] are based on the assumption of rational investor behavior. A number of researches show that many economic systems cannot be described with a sufficient degree of reliability by classical financial theories. Actually, the investor behavior is not strong rational and the majority of classical theories erroneously describe real systems [7, 9, 11]. Investigations of investor behavior in conditions of uncertainty and risk allow revealing a number of laws that have influencing to one of fundamental factors - "propensity to risk". The understanding of the factor "propensity to risk", studying the characteristics that influencing it, will enable to design mechanisms which will allow to consider the investor behavior.

For the decision of this problem it is necessary, firstly, to reveal principal causes of irrational behavior to analyze and supervise similar situations and as a result to avoid negative consequences of the "incorrect behavior". Secondly, it is necessary to predict in time and to estimate objectively other agents actions, using any deviations from a "rational" behavior.

In the paper the problem of irrational factors detecting has been decided. A set of investor's subjective factors has been revealed and their impact to investor behavior with using developed artificial intelligent model has been revealed.

\section{Rational decision-making theory: advantages and disadvantages}

The scientific basis for making decisions in different economic systems is economic theory. Economic science abounds in a variety of economic laws and patterns - demand (consumer choice theory) and supply (firm theory), diminishing returns (economies of scale), diminishing marginal utility. Knowing these universal relationships between events does not always make it possible to identify the causal 
mechanism connecting the economic agent's actions and the functioning of economic institutions with the predicted results by these theoretical laws $[14,17]$.

One of the provisions of the neoclassical theory is the rational behavior of economic agents. Its main content reduced to the fact that the agent has all the information he needs, has enough time to analyze it, and the decision he makes as a result maximizes some of his utility function, which is considered known. At the same time, utility is understood as a measure of the psychological and consumer value of different sets of goods. If one set of benefits is more preferable, then its utility will be greater. The utility function reflects the comparative consumer value of sets of benefits based on a preference relation. In this form, the rationality of behavior also enters into the hypothesis of an efficient market, on which many analytical techniques are based for practical application.

Studies of the economic agent's behavior have revealed a number of features that deny rationality in the sense of the above description. For example, the law of demand can be interpreted as a causal law explaining the economic behavior by the causes, preferences and beliefs of rational agents, as a result of which they (agents) form the causal mechanism according to which the demand for each commodity changes back to a change in the price of the goods. At the same time, the universality of the law of demand has exceptions in the form of Griffin's paradox, in which a negative effect of consumption on price change is observed. To implement practical goals, it is necessary to use individual demand curves that take into account the preferences and expectations of future prices, the consumer's money income and the prices of other goods. That is, the neoclassical theory of consumer choice explains the pattern of the negative slope of demand curves, while Griffin's goods, which have a positive slope in the demand curve, are rare.

The neoclassical firm theory uses the notion of a positive slope of supply curves using the price or issue factors as strategically significant and has the basic premise of maximizing profit under specified technology and demand constraints or maximizing the utility function including profit, free time, liquidity, prestige, or about the maximization of the total sales volume with the minimum acceptable production efficiency. However, in this description the firm represents entrepreneurs as economic agents seeking to maximize some index of preferences, including monetary and non-monetary benefits. This approach is similar to the approach to consumer behavior in the theory of demand, the utility of entrepreneurs is reduced to the observed monetary profit, while the risk factors and uncertainties, time, costs of obtaining information in the formation of the utility function are not taken into account.

The normative nature of the rational decision-making theory is to explain how to behave in order to be rational. The utility theory forms a number of formal conditions that the individual's preferences and choices should satisfy. To determine the essence of rational preferences and choice, it is necessary to give the subject a set of prescriptions in the form of these conditions (the prerequisites of utility theory) about how to prefer and make a choice rationally. This is the essence of the difference between the normative theory of decision-making and the positive theory, which, in turn, describes, predicts and explains the behavior of individual economic agents.

To take into account the uncertainty in decision-making, Neumann and Morgenstern introduced the notion of expected utility [12], taking into account the probabilities of each possible outcome in the evaluation of utility. However, common in all these areas is the development of the idea of rationality and a stable orderly structure of preferences in conditions of complete, accessible and qualitative information about the probabilities of the expected outcomes.

Thus, the initial prerequisite for studying the behavior of an economic agent in the process of consumption of economic goods in the normative theory of decision-making is the rationality of the individual, it is assumed that the consumer is a kind of personality deprived of personal qualities that makes rational economic decisions: weighs the quality of the product and its price, searches for options for the best ratio of these two parameters, and then makes a decision. But the rationality of an economic agent is limited, depending on its limitations on the perception and processing of information, attitudes and prejudices and depends heavily on the degree of involvement in the consumer choice process. This approach requires improvements and additional assumptions, for which it is necessary to attract excellent approaches and models of behavior of economic agents, on the basis 
of which it will be possible to identify the factors dominating in the behavior and to generate models with acceptable predictive ability.

Summarizing, we can say that the sources of uncertainty in the decision-making process are:

- Objective characteristics - lack of information, incompleteness of information resources, probabilistic nature of simulated processes, multivariate goals, criteria and alternatives;

- Subjective characteristics - low efficiency or incorrectness of the applied methods and technologies of data analysis, comparison and choice of alternatives due to subjective evaluation and interpretation of information, the disinclination of the person making the decision, responsibly perform all stages of decision-making.

As a result of the analysis carried out on the study of psychological factors, the violation of the rationality of the choice of decisions and their impact on the effectiveness of decisions, these factors are grouped in accordance with the structure of the decision-making process, as well as the preconditions for the manifestation of these factors. It should be noted that there are a lot of ways to classify these factors - by the degree of perception of information for decision-making, by the specifics of the subject area, etc. However, it seems more constructive for modeling and for more adequate assessment of the influence of subjective factors on the quality, timeliness and effectiveness of decisions taken Structuring the behavioral factors of the decision-maker in the enlarged stages of the decision-making process: 1 - identification of the target; 2 - collection of information and the formation of alternatives and criteria; 3 - formation of the attitude of preferences of alternatives; 4 choice of alternative.

\section{Factors of investor irrational behavior: the identification}

One of the major problem associated with understanding of investor behavior is to study the way in which he selects, analyzes and interprets the available information and then uses it to form some principles and beliefs. In other words, one must determine how the investor understands and comes to a definite decision.

As a result of the analysis of psychological factors [13-16], the violation from the rationality, these factors are grouped in accordance with the structure of the decision-making process, as well as the preconditions for the manifestation of these factors. It should be noted that there are a lot of ways to classify these factors - by the degree of perception of information for decision-making, by the specifics of the subject area, etc. However, it seems more constructive to model and more adequately assess the influence of subjective factors on the quality, timeliness and efficiency of decisions taken Structuring of the behavioral factors of the decision-maker in the enlarged stages of the decision-making process: 1 - purpose identification; 2 - information collection and alternatives and criteria forming; 3 alternatives preference relation forming; 4 - alternative choosing.

The first group includes factors of deviation from rational choice associated with the staging process - a problem situation description and the purpose forming. The definition of a goal requires significant, not always motivated costs and resources from the decision-maker, the impossibility, the difficulty of understanding and expressing an adequately informative goal that is the basis for decision-making, inconsistency:

- The factor of information representation consists in the difference in problem situation perception in case of its description in different formulations ("negative" or "positive"), and, consequently, in different preferences of alternatives corresponding to these two statements, which contradicts the rationality of the choice in making decisions;

- The factor of re-investment. When implementing investment projects, there is a periodic situation when the investor, investing a certain amount of financial, temporary resources, decides to continue financing to maintain its primary investments, even if the prospects for the project have deteriorated significantly. The probability of irrational investment of the project is directly proportional to the amount of invested money;

- Biased assessment of assets. The tendency of the subjects to attach greater importance to their own assets and to assign to them a higher cost, in comparison with the valuation of another's property. This effect is quite clearly manifested in the example of selling your own business, the 
value of which is estimated based on the effort and money spent on creating a business, without taking into account the economic indicators and the value of similar assets.

The second group includes factors and personality traits caused by difficulties in the formation of objective constraints in the choice of the analysis of possible options and the allocation among them is feasible. Personality traits that contribute to these deviations from rationality are dreaminess, impossibility or unwillingness to distinguish desired and real.

- Information flow factor. The decision-maker is often influenced by a large number of heterogeneous information, often unreliable and the opinions of other people, often incompetent in the problem at hand;

- The factor of conservatism. Delayed change by the decision-maker of established beliefs and principles under the influence of a new information flow;

- Use of incomplete and inaccurate information. In certain situations, limited information is perceived as exhaustive and sufficient. This leads to its misinterpretation and, as a result, to irrational decision-making;

- The tendency to subjectively perceive the situation. A biased evaluation of existing information forms a subjective, often erroneous, opinion and, as a result, erroneous decisions;

- incorrect use of instrumental methods of information evaluation. In the conditions of existence of necessary and sufficient information, individuals can use incorrect methods to assess it;

- The factor determinism. It manifests itself in a tendency to see patterns in situations in which there is in fact an accident. The desire to predict certain events inclines the decision-maker to describe situations with deterministic characteristics. A similar situation occurs when several similar events create a belief in the occurrence of a phenomenon;

- Propensity to simplification. If the complexity and uncertainty of the situation increases, the subject loses rationality and begins to use simplifications. In connection with the difficulties of processing a large amount of complex information, some of this information can be lost, which leads to a simplification of the task. However, unrecorded information often has a high degree of significance. This explains why fairly simple approaches work well on the market, and complex decision-making systems, even if applied, are not always adequate;

- The factor of simple access. The economic agent attaches too much importance to information to which there is simple access, so the frequent repeated use of such information can be perceived as an irrefutable truth;

- Subjective assessment of probability. There is a difference between the actual probability of an event and the way an individual evaluates this probability;

- The factor of "slow" changes. Greater weight is given to general, not absolute changes. Individuals may not take into account the non-standard behavior of the system, if it occurs gradually, at certain intervals in time;

- The factor of the greatest significance of recent events. The most recent events tend to be given much more weight. The entity may feel that the business is no longer working after a sequence of unprofitable trades, although in fact it continues to function within the computed profit-andloss relationships;

- Low propensity to change target goals. The essence of this effect is that in the subconscious of the individual there can be a conflict between his beliefs (assumptions) and the real reality. To avoid this, the subconscious tries to resolve this contradiction by "adjusting" historical facts to the existing beliefs. In other words, the human subconscious often "writes off" emerging problems on the "minor" shortcomings of the applied method, instead of pointing out the need for its modernization;

- Difficulties in choosing criteria and alternatives. Often such difficulties arise in individuals who are not prone to self-restraint or who are painfully related to external restrictions. In this case, virtual alternatives are formed, which can lead to undesirable consequences.

The third group integrates factors of personality traits leading to irrationality, and is associated with problems of evaluating the preferences of alternatives on a variety of criteria. On the subjective formation of transitive relations, the following factors influence the preferences of alternatives: 
- Accounting for differences, not similarities. In order to simplify the choice between different alternatives, individuals do not notice (ignore) the common features of phenomena, focusing on their differences. This can lead to different preferences for the same alternatives in the same situations;

- Nonlinearity of preferences. This effect is manifested in situations of comparison of possible amounts of profits or losses, at which the significance of the difference in absolute value between them is smoothed as the values increase;

- Giving more importance to growth than to absolute change. The individual perceives not so much the absolute value of his wealth as his change, and the losses always seem more significant than the equivalent income. Individuals are more likely to take a greater risk to avoid losses than to obtain additional profits.

The fourth group of irrational behavior factors is associated with the decision-making stage and is connected with such personality traits as caution, indecisiveness, radicalism, impulsiveness:

- Rejection of losses. The negative emotions experienced in connection with losses are much stronger than the positive emotions associated with making a profit. The investor gives twice the value of losses than profits. In reality, an investment project with the same probability of profit and loss will not be of interest to the investor, even if the profit is one and a half times more than the loss;

- The factor of risk - competence. Most decision-makers tend to take more risks in areas in which they are more competent, no matter how this competence and professionalism can influence the likelihood of a decision;

- Subjective control factor. The propensity of the subject to a greater risk in situations in which, in the opinion of this subject, there are real opportunities to influence the results of events. A similar situation develops if the subject needs to take a set of decisions that do not directly affect the future result;

- Propensity to take risk depending on previous financial results. The degree of risk aversion largely depends on previous results (for example, investment decisions). If they were positive, then the risk aversion may temporarily decrease, and vice versa, after a succession of failures it only aggravates, leads to the appearance of "fear of mistakes";

- Increased risk for net profit. The individual is inclined to take a much greater risk when investing the funds of previous financial transactions. The propensity to risk the profit received from investing is increasing;

- The factor of choice of alternatives is manifested in the fact that when all alternatives are presented simultaneously, the subject chooses certain of them on some principle, and if the alternative is sequentially provided, he concentrates his choice on one of them.

The diagram of the cause-effect relationship of the factors of the investor's irrational behavior reflects the most significant factors and is presented in fig. 1.

Thus, there is a significant set of personal, psychological characteristics of economic agents that cause significant deviations from rationality in the choice of solutions. The individual, in whose behavior the listed features are clearly expressed, does not take into account the whole set of available information about the problem, in fact making the boundaries of the objective function, decision criteria, limited many alternatives, or unreasonably exposing them as the best part of them.

The revealed effects and patterns of behavior of economic agents in conditions of uncertainty and risk allow to explain many facts of economic agents irrational behavior. Especially brightly, irrational behavior manifests itself under uncertainty and risk in entrepreneurial, investment, innovation, and financial activities. Risk propensity is one of the most significant factors in the implementation of investment activities of innovative projects. The studying of factors influencing propensity to risk, determining the degree of their significance, provides certain possibilities for using this knowledge to influence the behavior of the economic agent (decision-maker).

In order to model the agents' behavior and take into account the consequences of irrational decisions arising from the occurrence of these deviations (errors), it is necessary that the modeling scheme include the following independent models: the model for controlled object, the model for 
decision-maker, the model for generate alternatives. In microeconomic modeling, the enterprise acts as an object if a decision is made to implement an investment project for the modernization of fixed assets, the release of new products, optimization of the structure of output, etc. The model of the object reflects the influence of the decisions made on the controlled object. The model of the subject (decision maker) reflects the existing psychological, cognitive features of the subject and the structure of the factors of the decisions made. The model of alternatives presents a description of attributes and alternatives and reflects the evaluation of options from the perspective of goals and selection criteria and the structure of their set. An example of the application of decision-maker model is shown below.

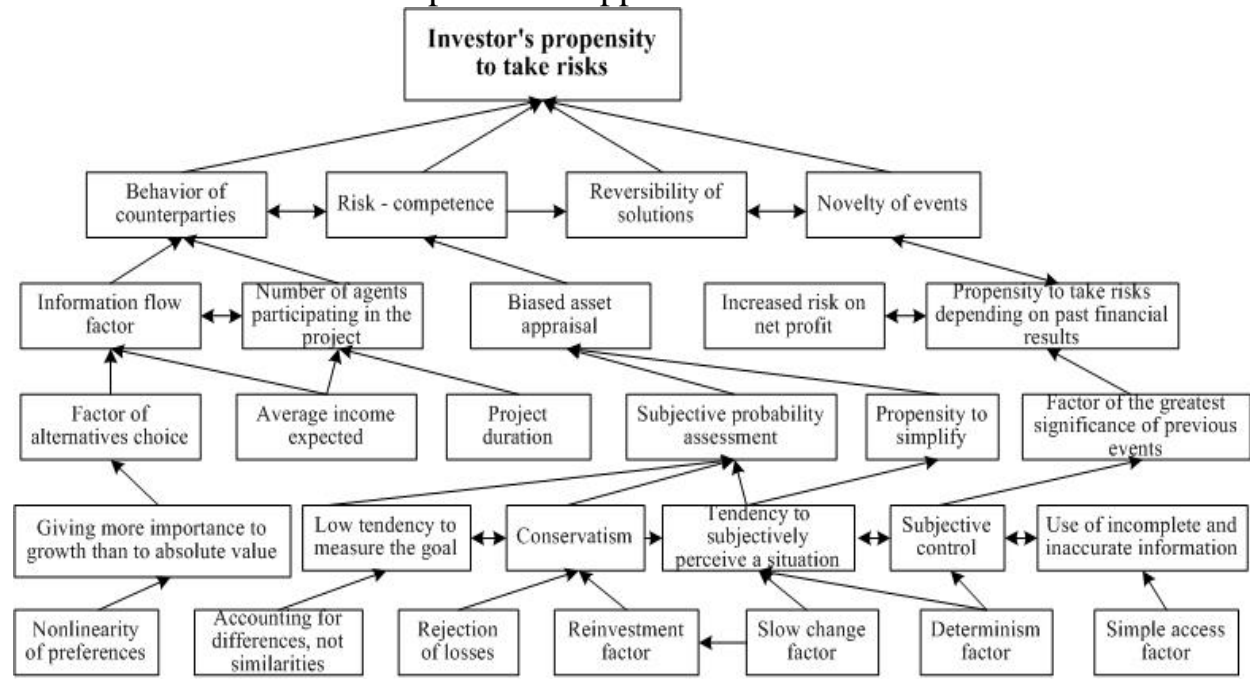

Figure 1. Cause-effect relationship of subjective factors of the investor's propensity to take risk.

\section{The model for decision making}

The propensity to take some decision differs for each decision maker. It coordinates by objective external and internal constraints which include:

- Objective environment factors;

- Internal research object factors;

- Demand, pressure of economic partners, competitors, consumers;

- Legislative regulatory restrictions that determine the liability (administrative, financial) for the management functions and regulatory between participants in the economic process;

- Social and moral obligations as determined goal that is implementation of the event will be successful.

The decision to choose is influenced by the relationship to decision maker to the described factors. One of the major unsolved problems of decision-making process modeling is the problem of subjectivity, which is not described by classical mathematical methods. To solve these problems a utility functions are used. In analyzing a decision in finance on the investor behavior the rational choice theory is usually used. It is based on the approach generated optimization model. Rational behavior is behavior which provides the best decision in terms of a particular purpose. As shown above a number of decisions based not only on rational considerations, but also in social traditions, subconscious reactions, moral installations scattered facts of personal experience in some field, and are the result of irrational behavior. Under high degree of uncertainty economic agents are not able to analyze the whole complex of factors and goals, and often apply special fragmentary discourse.

Classical analytical approach does not involve consideration of subjectivity in the decisions making, not investigate reasons and methods of mutual influence in the construction of economic evaluations.

To solve the problem of decisions selection about investment strategy we take into account the different risk propensity of potential investors and use tools based on the utility function of NeumannMorgenstern [12]. To construct a utility function it is necessary to determine the nature of the behavioral study of alternatives influences on the functions type, as well as consider the impact of subjective factors to the risk propensity. 
Practical application of utility theory in assessing of investment projects attractiveness identifies the following advantages of utility curve:

- as the expression of individual investor (expert) preferences utility curve once being built can make investment decisions in the future, taking into account their preferences, but without any consultation with expert;

- in general utility function can be used to delegate the decision making. It is logical to use a utility function of top management as to ensure its position in the decision it seeks to take into account the conflicting interests of all contractors. The utility function may change over time, reflecting the financial terms. Thus, utility theory can be formalized approach to risk and thus research to justify decisions taken under uncertainty and risk.

Because of the complex cause-effect relationship of subjective factors, irrational behavior, and risk propensity to determine the impact of factors it is appropriate to use artificial intelligence (AI) methods [16, 18-20]. With the help of fuzzy set theory the AI model was developed which allows to analyze and evaluate the impact of subjective factors for investors' risk propensity.

The implementation of fuzzy model is carried out in Matlab environment using the module Fuzzy Logic Toolbox [13, 14]. The simulation results are used in construction the utility functions of investment projects. The input data serves 25 parameters - subjective factors. Initial data processed by the system and generates an output variable is the risk propensity. All variables in the model are normalized in the interval from 0 to 1 . The membership function is constructed for the resulting parameters "risk propensity" and "counterparty behavior". A rules base consist of 100 rules and has a form of "if-to" records and reflects different combinations of interconnection all input factors (irrational factors) and output (result) indicator "risk propensity". As shown above subjective factors of the investor's risk propensity have a complex relationship. Therefore, the input variables are in turn the resulting parameters for the factors of the lower hierarchical level.

Table 1. Simulation results.

\begin{tabular}{ccccccccc}
\hline $\begin{array}{c}\text { Experi } \\
\text { ment } \\
\text { No. }\end{array}$ & $\begin{array}{c}\text { Risk }- \\
\text { Com- } \\
\text { petence }\end{array}$ & $\begin{array}{c}\text { Reversibil } \\
\text { ity of } \\
\text { solutions }\end{array}$ & $\begin{array}{c}\text { Novelty } \\
\text { of } \\
\text { events }\end{array}$ & $\begin{array}{c}\text { Behavi- } \\
\text { or of } \\
\text { counter } \\
\text { parties }\end{array}$ & $\begin{array}{c}\text { Number } \\
\text { of } \\
\text { counterp } \\
\text { arties }\end{array}$ & $\begin{array}{c}\text { Biased } \\
\text { asset } \\
\text { appraisal }\end{array}$ & Profit & $\begin{array}{c}\text { Risk } \\
\text { propensity }\end{array}$ \\
\hline 1 & 0.055 & 0.095 & 0.985 & 0.145 & 0.975 & 0.115 & 0.155 & $\mathbf{0 . 1 4 7}$ \\
2 & 0.185 & 0.095 & 0.965 & 0.145 & 0.955 & 0.115 & 0.155 & $\mathbf{0 . 2 0 2}$ \\
3 & 0.205 & 0.175 & 0.925 & 0.195 & 0.935 & 0.145 & 0.225 & $\mathbf{0 . 3 4 1}$ \\
4 & 0.205 & 0.185 & 0.925 & 0.225 & 0.915 & 0.145 & 0.225 & $\mathbf{0 . 3 5 9}$ \\
5 & 0.245 & 0.205 & 0.855 & 0.245 & 0.875 & 0.225 & 0.245 & $\mathbf{0 . 4 0 3}$ \\
6 & 0.285 & 0.245 & 0.835 & 0.285 & 0.835 & 0.265 & 0.275 & $\mathbf{0 . 4 3 4}$ \\
7 & 0.325 & 0.305 & 0.775 & 0.315 & 0.785 & 0.315 & 0.315 & $\mathbf{0 . 4 6 4}$ \\
8 & 0.355 & 0.325 & 0.775 & 0.345 & 0.785 & 0.335 & 0.335 & $\mathbf{0 . 4 7 6}$ \\
9 & 0.385 & 0.355 & 0.765 & 0.385 & 0.765 & 0.375 & 0.365 & $\mathbf{0 . 4 9 4}$ \\
10 & 0.425 & 0.365 & 0.625 & 0.395 & 0.625 & 0.415 & 0.385 & $\mathbf{0 . 5 3 2}$ \\
11 & 0.425 & 0.395 & 0.475 & 0.415 & 0.485 & 0.455 & 0.435 & $\mathbf{0 . 5 8 5}$ \\
12 & 0.455 & 0.435 & 0.415 & 0.445 & 0.455 & 0.475 & 0.465 & $\mathbf{0 . 6 0 5}$ \\
13 & 0.505 & 0.475 & 0.395 & 0.495 & 0.435 & 0.515 & 0.495 & $\mathbf{0 . 6 4 5}$ \\
14 & 0.625 & 0.615 & 0.375 & 0.615 & 0.405 & 0.635 & 0.635 & $\mathbf{0 . 6 5 5}$ \\
15 & 0.735 & 0.745 & 0.345 & 0.775 & 0.385 & 0.745 & 0.705 & $\mathbf{0 . 6 8 5}$ \\
16 & 0.755 & 0.795 & 0.315 & 0.805 & 0.345 & 0.775 & 0.725 & $\mathbf{0 . 7 1 7}$ \\
17 & 0.795 & 0.795 & 0.295 & 0.805 & 0.325 & 0.775 & 0.765 & $\mathbf{0 . 7 2 3}$ \\
18 & 0.835 & 0.815 & 0.285 & 0.835 & 0.285 & 0.825 & 0.815 & $\mathbf{0 . 7 9 2}$ \\
19 & 0.885 & 0.845 & 0.255 & 0.865 & 0.255 & 0.875 & 0.855 & $\mathbf{0 . 8 8 1}$ \\
20 & 0.915 & 0.885 & 0.235 & 0.925 & 0.235 & 0.915 & 0.895 & $\mathbf{0 . 9 6 1}$ \\
21 & 0.915 & 0.915 & 0.195 & 0.955 & 0.195 & 0.925 & 0.925 & $\mathbf{0 . 9 6 5}$ \\
22 & 0.935 & 0.925 & 0.135 & 0.975 & 0.165 & 0.955 & 0.955 & $\mathbf{0 . 9 8 5}$ \\
23 & 0.975 & 0.965 & 0.135 & 0.985 & 0.135 & 0.975 & 0.995 & $\mathbf{0 . 9 9 5}$
\end{tabular}


The simulation result is represented as the vector of values of variation of subjective factors (input variables) and assessing of parameter "risk propensity" (output variable), table 1.

As shown in fig. 2 the curve that determines the dependence of the variable "profit" and investors' "risk propensity", has three different areas.

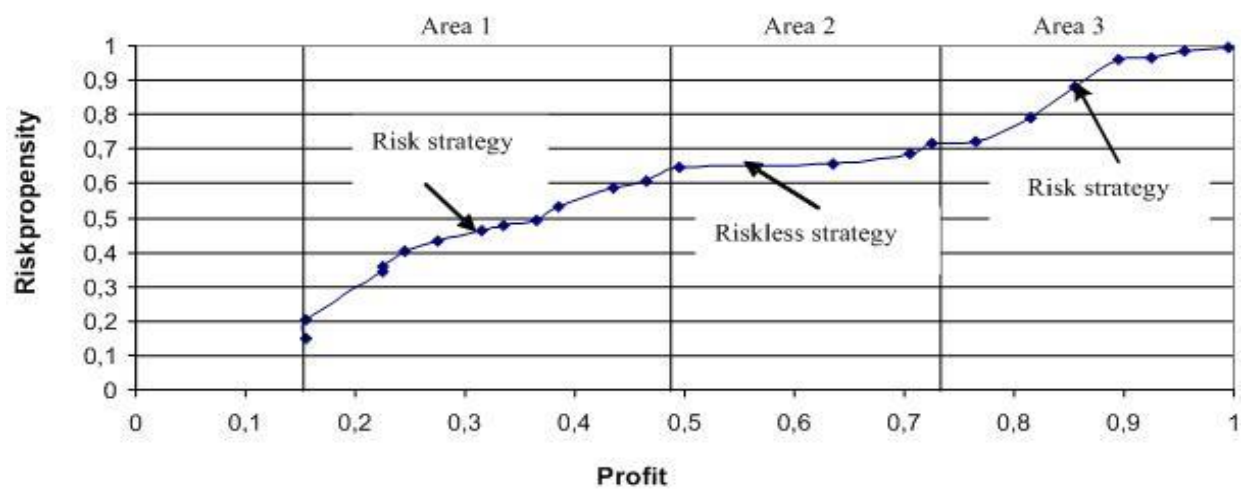

Figure 2. Utility function.

Area 1: Strategy of risky investment. Under the profit increasing the risk propensity has the tendency of significantly growth. Changing the low profits significantly affect the decision.

Area 2: Strategy of risk-free investment. Under the profit increasing the parameter "risk propensity" is practically unchanged. The mean change in income has weak effect on the decision.

Area 3: Strategy of risky investment. Under profit increasing the risk propensity has the tendency of significantly growth. The profit growth significantly affects the decisions.

Thus, based on AI model the impact of subjective factors on the risk propensity were determined. The results can be used in construction of utility functions of investment projects, taking into account the influence of subjective factors on the tendency of decision-makers to take risks.

Due to the application of AI model the problem of impact of subjective factors on the investor's risk propensity was solved. With the help of fuzzy modeling of the expert system, a fuzzy model was developed that makes it possible to analyze and evaluate the influence of subjective factors of the investor's propensity to take risks for the final decision adoption. The obtained results can be applied for constructing the utility functions of innovative projects that take into account the influence of subjective factors of the propensity of the decision maker to risk.

\section{Results and conclusions}

The transformation of methodological approaches in the decision-making theory in the study of the economic agents behavior is considered. The impossibility of an isolated using of rational choice theory as an adequate description of economic activity due to the objective existence of a multitude of causes of the irrationality of the decision-maker is shown. The main factors of the individual's irrational behavior, structured according to the stages of the decision-making process, based on the economic agent's personality-stable psychological features are selected and systematized. The AI approach for taking these effects in the decision making is proposed.

Given the complex causal relationship of irrational factors and to determine the degree of their influence on the investor's risk propensity, the fuzzy model is proposed. This model is used to construct the utility function, which is an objective basis for selecting behavioral alternatives. The practical use of the utility function can be found in the problems of economic decisions selecting. This will improve the quality and effectiveness of management decisions.

\section{References}

[1] Hausman D 2012 Philosophy of the Economy (Moscow: Publishing House "Anthology") (in Russian)

[2] Hands U 2012 Regulatory Rational Choice Theory: Past, Present and Future Problems of Economics 10

[3] Friedman M 2003 Freedom (Moscow) (in Russian) 
[4] Van Horne and James C 2000 Finance Management (Moscow) (in Russian)

[5] Rusavin G I 2005 Theory of Rational Choice and its Limitations Issues of Philosophy 6 (in Russian)

[6] Rudic N B 2009 Behavioral Finance in Economy (Moscow) (in Russian)

[7] Blaug M 2004 The methodology of economics or how economists explain (Moscow) (in Russian)

[8] Kahneman D, Tversky A 2003 Rational choice, values and frames Journal of Psychology 4

[9] Piskunov L P 2012 Transformation of Theoretical Approaches to the Study of Consumer Behavior Science and Business: the Ways of Development 9

[10] Glukhov B 2010 Household Finances: Structure and Management Problems of the Theory and Practice of Management 1 (in Russian)

[11] Kleiner G B 2003 Modeling Methodology of Decision-making by Economic Agents Economics and Mathematical Methods 2 (in Russian)

[12] Neumann D, Morgenstern O 1970 Theory of Games and Economic Behavior (Moscow)

[13] Orlova E V 2012 Modeling of Utility Function With Using Irrational Factors St. Petersburg State Polytechnical University Journal. Economics 3 24-30 (in Russian)

[14] Orlova E V 2014 Economic Behaviour: Synthesis of the Rational and the Irrational Problems of Theory and Practice in Management 3 127-136 (in Russian)

[15] Orlova E V 2016 Modeling and Decision Support for the Firms' Pricing Policy under a Chaotic Dynamic of Market Prices Proceedings of the Workshop on Computer Modeling in Decision Making 1726 81-88

[16] Orlova E V 2016 Simulation Model for the Firms' Financial Resource Management Proceedings of the 28th International Business Information Management Association Conference on Vision 2020: Innovation Management, Development Sustainability, and Competitive Economic Growth 1317-1321

[17] Orlova E V 2017 Control over Chaotic Price Dynamics in a Price Competition Model Automation and Remote Control 78(1) 16-28

[18] Soldatova O P, Lyozin I A, Lyozina I V, Kupriyanov A V and Kirsch D V 2015 Application of fuzzy neural networks to determine the type of crystal lattices observed on nanoscale images Computer Optics 39(5) 787-795 DOI: 10.18287 / 0134-2452-2015-39-5-787-794

[19] Orlov E P and Sizova I M 2016 Analytical representation of statistical characteristics of random processes with arbitrary spectra Computer Optics 40(4) 560-571 DOI: 10.18287 / 2412-61792016-40-4-560-571

[20] Amosov O S, Ivanov Y S and Zhiganov S V 2017 Human localization in the frame of the video stream using an algorithm based on growing neural gas and fuzzy inference Computer Optics 41(1) 46-58 DOI: 10.18287 / 2412-6179-2017-41-1-46-58 